\title{
Routing and Security Issues in U-Healthcare Mobile, Ubiquitous and Wireless Body Area Network (WBAN)
}

\author{
Jawad Ahmad Aman ${ }^{1}$ and Abdul Salam Shah ${ }^{2 *}$ \\ 1,2 SZABIST, Islamabad, Pakistan \\ 1jawadaman211@gmail.com, ${ }^{2 *}$ shahsalamss@gmail.com
}

\begin{abstract}
The ratio of aging and chronic diseases is increasing day by day; therefore, the people are interested in better health management. They are interested in patient-centered methods instead of the traditional and conventional hospitalized services. The idea of $U$ Healthcare is getting popularity. The U-Healthcare is responsible for the observations of different states of health during running, walking, and jogging. Researchers and developers are focusing on a telemedicine system composed of Mobile, Ubiquitous and Wireless Body Area Network. The U-Healthcare system is still a little bit vague and obscure, and due to the shortcomings, the complete adoption of the U-Healthcare system is not possible. So, for this purpose, we just need to take the inclusion of latest, wellsophisticated hardware, communications, interconnections, trademark computing, advanced routing and privacy to the upcoming child of U-Healthcare based on Mobile, Ubiquitous and Wireless Body Area Network. In this paper, we have critically analyzed the relevant papers on Mobile, Ubiquitous and Wireless Body Area Network specifically in terms of the routing and security issues.
\end{abstract}

Keywords: Headband Devices, Mobile, Routing and Security, Sensors, Ubiquitous and Wireless Body Area Network, U-Healthcare

\section{Introduction}

The better health management always remained a concern for human beings. Because of the growing rate of critical diseases, it will be difficult for the doctors to attend a huge number of patients individually. There are two types of illnesses, i.e. short term and the long term divided based on the time of recovery from the disease. The short-term illness can be cured easily but the treatment of long-term illness requires a lot of attention, enough amount of time and proper medications. Due to long-term illnesses, future communities will be more health and fitness aware and the societies will look for greater health and fitness management. The people will prefer patient-centered approach, rather than conventional, the clinic focused health and fitness services [1]. After the progress of telemedicine in the typical E-Health to M-Health, researchers are progressing towards UHealth. Despite the current efforts in U-Healthcare, due to its shortcomings, it has not been adopted completely [2].

The term U-Healthcare means "Ubiquitous processing implies brilliant surroundings constructed from lots of computer system pieces which will supply needed details to be able to the person who requires the item at the proper period" [3]. The human population is growing rapidly which may increase problems for the U-Healthcare system and it will be difficult to handle the increasing size of the database of patients. The traffic on the network will also increase the problems of routing, security, and bandwidth. In the traditional health system, the patient must visit the clinic for checkup or treatment, while

Received (December 10, 2016), Review Result (March 7, 2017), Accepted (December 2, 2017)

* Corresponding Author 
the U-Healthcare system allows doctors to remotely check the patient's files in real-time and provide suggestions [4].

The U-Health system is consisting of the Tier-1 (WBAN), Tier-2 (Base place or perhaps Personalized Server) and Tier-3 (Remote Server). Tier-1 identifies the Wi-Fi connection with body sensor nodes and Access point (AP), Tier-2 link the WBAN sensors towards the U-HEALTH, 3G/4G or LAN. The Tier-3 provides real-time checking of the facts towards the medical doctors and helps to store the patient's facts to the hospital's repository intended for medical data [4]. Almost every healthcare system has basic components illustrated in following figure 1 taken from reference [5]. The sensors are used for the sensing or calculations of health parameters like blood pressure, body temperature and heartbeat rate of the patient. The wireless network is used for the transmission of data from the handheld device attached with the healthcare system to the database of the hospital. The doctor can access the data stored in the database system through his personal computer or handheld device. Some systems also send the SMS alert to the doctor in case of emergency for the quick response [5].

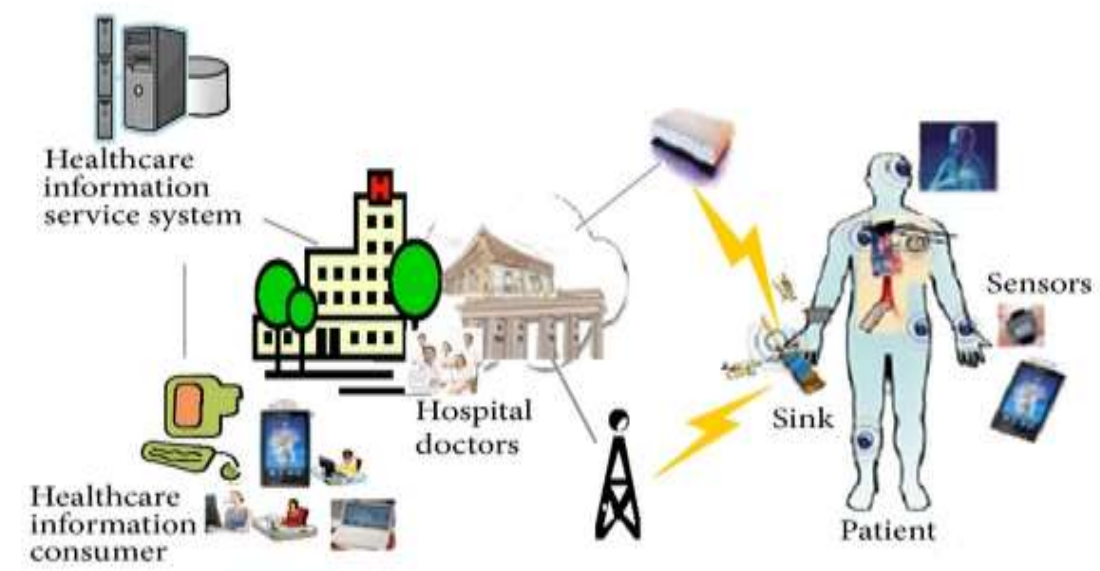

Figure 1. Basic Components of a Typical Healthcare System [5]

In a normal U-Health method, detectors like ECG, EEG, EMG, motions/positioning, along with the body's temperature forward the files by using the wireless interface to a starting place. For the transmission of data 3G, U-Health, WLAN, LAN or perhaps GPRS/SMS networks have been used [4].

Healthcare systems provide some advantages like mobile health monitoring, a centralized database, wireless connectivity, computerized monitoring, and SMS notifications, but still some issues exist due to which further improvements are required so that healthcare systems can be properly implemented. The issues are mostly related to the networks used for the transmission of data [6].

The success of the healthcare systems depends upon the reliable network because most of the wireless networks are not highly secure. The data on the network is always exposed to the external attacks until unless a secure encryption method has not been used. The security of the data of a patient's meaningful data is important, the data should not be accessed by an unauthorized person. The authorized persons may be a doctor, nurse and patient. The healthcare systems mostly use cloud which is not secure the data can be accessed by a third party unauthorized person [7]. To explore the security and routing issues a detailed critical evaluation of the proposed healthcare systems has been carried out to overcome the shortcomings of the proposed systems and a reliable and most secure security mechanism can be embedded. 
In this paper, we will analyze the already proposed model, and identify their limitations. The structure of the remaining paper is organized as; the Literature Review is presented in Section 2, the Critical Evaluation table is provided in the Section 3, and finally, the Conclusion and Future work is provided in Section 4.

\section{Literature Review}

Grgic et al., in [1] discussed the uses of wireless sensor networks and body area sensor networks. The sensors are responsible for the wireless sharing of information based on ZigBee, they consume very low energy that's why are suitable to be used with healthcare systems. Individuals have their own history of information, stored in the secure environment within the limited approach to information history. The approach to information history is based on the rule and regulations, laws and principles of the organization. The environment is about the continuous observations of patients. The safety, assurance, and secrecy of information are the issues associated with this type of telemedicine approach. It must be insured by the system that the information can only be accessed by legitimate users like doctors, nurses, and patients. The information can also be retracted if the hop device does not work properly. The CodeBlue is the already deployed continuous observation telemedicine assemblage of objects in the field of medical sciences.

Kambourakis et al., in [2] discussed the routing and security issues in the CodeBlue framework. In the CodeBlue the position of a patient can be traced using a decentralized RF-based tracking system. The CodeBlue is composed of small sensor hops which are used for the observation of different health indicators. Like other technologies, the CodeBlue is also exposed to external attacks. In the Denial of Service (DoS), the attacker sends continuous requests on the network to increase the data traffic beyond the control of the network link which may lead to risk the patient's life in case of severe emergency. The stealth DoS is used to separate/isolate some nodes of a network. The attacker tries to disturb the routing of the network through Routing loops attack by modifying routing addresses. The attacker sends bogus packets claiming to have the shortest path this attack is known as black or grey holes. In snooping attack the eavesdropping and location attacks are common in CodeBlue. In the modification attack, the attacker tries to modify the network traffic or even in stealth high jacking the attacker diverts the data to the nodes which he controls.

Kim et al., in [4] proposed a U-healthcare system using the smart headband. The system can monitor the health state in running and walking conditions. The system has the capability to inform the relatives or family members of the patient in case of an emergency. The health monitoring system was installed on a handheld computer. The system has two main components a smart headband and operating system. The headband has the capability to measure physiological signals. The headband and monitoring program were connected through wireless communication through ZigBee protocol. The adaptive noise cancelation has been used to reduce the noise of the signals.

Ko et al., in [8] disseminated the difficulties in sensors and proposed solutions to overcome these issues. The sensors facilitate doctors and nurses to take care of patients. The medical sensing has been advanced in technologies like imaging, and lab on a chip. Conventionally medical sensors were costly and complicated, but due to the enhancement in the fields of computing and microelectronics the medical sensors are manageable and accessible. The sensors can be easily connected with modern technologies. As compared to the wired sensor network, the hardware of wireless sensor networks is less noticeable and have more permanent and standard inter-connectivity.

Aminian et al., in [9] discussed the entire structure of a human sensor interconnected objects. This paper presents the idea of the treatment center that can be available everywhere for communication about the casualties. The system has four basic 
components which are responsible for the collection of signs, dispatching of healthrelated information, getting and forwarding information through the wire to the small digital computer used by the physician. Each component of the system is responsible for fulfillment of the unique task like measurement of blood pressure, the ratio of heartbeats, etc. For the measurements, the patient's body should be in a horizontal state. Whenever the patients are found without the determined positions the output of the system will be zero because of zero sensing. To determine the format and transmission, TDMA has been adopted due to the consistency of the core and sub-parts of the system.

Wagh et al., in [10] proposed a wireless body area network which operates with the help of sensors for the observations of important indications like fever, blood pressure, or electrocardiographs. The objects are composed of different phases like foundation phase, accumulator, base station phase, and web-based phase. The communication between the patient and physician take place wirelessly. In the foundation phase, the sensors are implanted in the patient body together with the information in the form of different functions, characteristics, actions towards progress, proceedings. The information from the accumulator sensor transmitted to the base station phase which is consist of a hardware having memory. The base station dispatches the complete data to a device that collects the meaningful data from distinct sensors and share it with the patient and doctor. The meaningful data is saved in the record of patients and dispatched to the computer system of physician present in the healthcare center.

The entire system is interlinked through the wireless channel for dispatching of information about key indications of the patient's health. The unsuccessful connection of routing due to the violent clash between hops, unavailability of hop and other tragedies due to which continuous sharing of information is impossible, which further diverts the attention of the developers, inventors toward multipath environment for such wireless group of objects. The two most key hurdles in the system are the uninterruptable manner ability of body sensors hops for performing something and another one ensures that the information is dispatched to the targeted individual.

Khan et al., in [11], discussed the instant sensor community about professional medical health. The WSN replaces large medical machines with few detectors. Reduces normal visits of affected individuals to medical professionals. The development associated with WSN technologies in health-related software offers reduced the specific severance to a larger degree. A radio physique spot network is often a special sensor system designed to operate autonomously to get in touch with medical receptors and devices, found inside and away from a body of a human.

The WBAN provides easily transportable applications which could shift with the individual. Actual instant receptors are usually either implanted in the individual system or even attached to all of them because they are un-obstructive wearable. A variety of receptors are made to detect medical impulses including ECG, PPG, EEG, beat fee, blood flow, pressure, and temperature. For supervising risky diseases, these types of software continuously check the patient's physique from the critical indicators of sickness as well as document data to help regional server. The limitations and challenges are also related to implementations of detector environment energy use, protection/safety, problem tolerance, the level of privacy, the good quality associated with support (QoS), and effective reply.

Movassaghi et al., in [12] disused the redirecting methodologies inside WBAN. The redirecting practices engage in a vital purpose inside the general system performance with regards to hold up, strength consumption and heat. Specific troubles involving BANs needs the planning and new redirecting practices for BANs. Several course-plotting practices are already recommended regarding BANs. The first type can be temperature centered course-plotting practices that are generally built to minimize the neighborhood or even all-round system temperature to increase. The bunch centered course-plotting practices which in turn try to partition nodes throughout BANs to distinct groupings along 
with allocated cluster-head for each bunch along with options data by the sensor on the torpedo through the cluster-heads. These kinds of practices try and minimize the volume of direct transmissions by devices on the foundation station. Nonetheless, lots of overhead along with hold of essential for bunch variety tend to be primary negatives of these practices.

Chung et al., in [13], discussed conceptual architecture on the designed Wi-Fi sensor community (WSN) dependent u-healthcare technique which comprises pass on nodes with threshold and cell phone node. The person or perhaps older donning bio-shirt with the linked cell phone node may possibly go out of constrained transmission selection of WSN. The distinct types of routing methods regarding sensor sites may be labeled as sometimes cluster-based hierarchical or smooth. Data confirming within WSN is application dependent. Data confirming may be labeled as sometimes time-driven, eventdriven, query-driven or a crossbreed coming from all these methods. The sensor nodes will occasionally switch on detectors and transmitters, sense and transmit the results connected with curiosity on constant time periods. Throughout event-driven and querydriven methods, sensor nodes behave instantly to help immediate and extreme adjustments inside the worth of a sensed characteristic due to the occurrence of a selected celebration, or answer the problem produced through the basic train station or a different node inside the circle. To stretch the system lifetime, course-plotting methods for Wi-Fi sensor sites in professional medical environments must be equally intermittent schedule constant checking along with event-driven checking. On the findings, bi-directional MCF standard protocol indicates the ideal wireless box wedding party rate of $96.5 \%$. This fresh result implies that formulated bi-directional MCF standard protocol is an extremely dependable standard protocol with the mix of both professional medical information.

Kumar et al., in [14] proposed healthcare monitoring system using wireless sensor network to tackle the issues like packet losses and congestion in long-distance communications. They have also highlighted the issue of the load on the central server in case of the increase in many patients. Authors have designed an on-Board Decision System (BDS) to make the decision based on the patient's data. The software side contains an Ethernet module and GSM/GPRS module. The designed gateway contains the central control unit, a database, WSN module, WLAN AP, and GSM module.

Rajeswari in [15], proposed a model for healthcare monitoring based on the wireless sensor network and GSM module and micro-controller module. The system manages data of each patient with ID in the database system. For the data assessment from the database, the web page has been used through which the doctor can manage the data of a patient.

Vijayalakshmi et al., in [16] proposed wireless mesh network based on sensors for the patient monitoring system. The LCD connected to the system provides information about the health parameters of the patient. Zigbee technology has been used to transmit the data to the computer of the doctor. The system also notifies the doctor through SMS. The separate devices for each patient are required.

Babu et al., in [17] proposed Open Geo-Spatial Consortium (OGC) model based on a cloud for the monitoring of the health of a person. The method has the advantage as the sensors output data is transported through the cloud which is available at any time with ease to the doctor to tackle in case of an emergency. The sensors for blood pressure, body temperature, heart rate, respiration rate, oxygen saturation in the blood (spo2), and ECG has been placed on the body. The approach used 52 degrees north SOS software [18] and MySQL for the data management on the cloud. Cloud Bee Infrastructure has been used for the deployment of healthcare data on cloud [19].

Neves et al., in [20] highlighted the uses of wireless sensor networks in healthcare systems. The physical presence of the patient at the clinic is not required in healthcare systems because the Body Sensor Network (BSN) sends patient data continuously to the database accessible to the doctor, which can be easily accessed by the doctor. The 
complete medical history of the patient can be easily managed in a single database for future use.

\section{Critical Evaluation}

The detailed critical evaluation of each technique has been carried out the summary of the same is provided in Table 1.

Table 1. Critical Analysis

\begin{tabular}{|c|c|c|}
\hline $\begin{array}{l}\text { Ref. } \\
\text { No. }\end{array}$ & Weakness & hs \\
\hline [1] & $\begin{array}{l}\text { - Safety, assurance of information } \\
\text { belonging to sickly individual } \\
\text { means meaningful data only be } \\
\text { accessed by the legitimate } \\
\text { personnel like doctors, nurses and } \\
\text { secrecy of information belonging } \\
\text { to sickly individual means data } \\
\text { related with sufferer must be kept } \\
\text { secret. } \\
\text { - Safety, assurance of information } \\
\text { belonging to sickly individual is } \\
\text { not ensures in these systems. } \\
\text { - Secret information belonging to } \\
\text { sickly individual can be accessed } \\
\text { by the hacker. }\end{array}$ & $\begin{array}{l}\text { - Fast gradual advancement in } \\
\text { telemedicine environment means due } \\
\text { to the WSN \& WBAN phase by phase } \\
\text { enhancement make the professional } \\
\text { medical center is so productive, tools } \\
\text { of low expenditure of energy (ZigBee } \\
\text { based), direct contact. } \\
\text { - Fast gradual advancement/growth of } \\
\text { telemedicine environment. } \\
\text { - Low expenditure of energy (ZigBee } \\
\text { based). } \\
\text { - Straightforward link to the sickly } \\
\text { individual. } \\
\text { - Continuous observations of sickly } \\
\text { individuals without any break. }\end{array}$ \\
\hline [2] & $\begin{array}{l}\text { - The security related tasks have not } \\
\text { been done yet in the CodeBlue. } \\
\text { - The performance of CodeBlue } \\
\text { decreases if formed through adhoc } \\
\text { network in external environment. } \\
\text { - Different types of attacks are } \\
\text { possible in Code Blue like Denial } \\
\text { of Service (DoS), Stealth DoS, } \\
\text { black or grey holes, snooping } \\
\text { attack, eavesdropping and location } \\
\text { attacks. } \\
\text { - The CodeBlue is suitable to be } \\
\text { used inside the hospitals with fixed } \\
\text { network. }\end{array}$ & $\begin{array}{l}\text { - In the CodeBlue the position of a } \\
\text { patient can be traced using a } \\
\text { decentralized RF-based tracking } \\
\text { system. } \\
\text { - The subscription is needed before } \\
\text { receiving and sending of data. } \\
\text { - Every node in CodeBlue maintains the } \\
\text { node table index for the routing. } \\
\text { - The sender can request for specific } \\
\text { path before transmission of data. } \\
\text { - The CodeBlue devices can be used as } \\
\text { adhoc network. } \\
\text { - The CodeBlue performs better inside } \\
\text { the hospitals in fixed environment. }\end{array}$ \\
\hline [4] & $\begin{array}{l}\text { - The health care monitoring system } \\
\text { only operates with UMPC devise. } \\
\text { - The authors have not explained } \\
\text { that how the doctor or family } \\
\text { members of the patients will know } \\
\text { about the location of the patient. } \\
\text { - The system should be installed } \\
\text { with other devices so that } \\
\text { maximum benefit can be achieved. }\end{array}$ & $\begin{array}{l}\text { - The headband is the most suitable } \\
\text { device for the system because the } \\
\text { forehead is the most stable than other } \\
\text { organs of body. } \\
\text { - The implementation of measurement } \\
\text { device in headband is much easier. } \\
\text { - The ZigBee protocol has been used } \\
\text { which is low powered, low cost and } \\
\text { easy handled wireless protocol. } \\
\text { - The adaptive noise cancelation will } \\
\text { reduce the noise of the signals. }\end{array}$ \\
\hline
\end{tabular}




\begin{tabular}{|c|c|c|}
\hline [8] & $\begin{array}{l}\text { - Reliability or Stability is the issue } \\
\text { with system. } \\
\text { - Comfort (Privateness) and Security } \\
\text { (Protection) is another major issue } \\
\text { with the system. } \\
\text { - The other major issue is the Source } \\
\text { Shortage (Deficiency). }\end{array}$ & $\begin{array}{l}\text { - Medical sensing. } \\
\text { - Proper utilization of treatment center. } \\
\text { - Achieve knowledge about distinctive } \\
\text { supervising devices just like bodily } \\
\text { supervising. }\end{array}$ \\
\hline [9] & $\begin{array}{l}\text { - Ahead or outside of the boundary } \\
\text { leads to no collections of } \\
\text { meaningful data. } \\
\text { - Determination of the fixed and } \\
\text { specific positions, influence } \\
\text { productivity of the system. } \\
\text { - Sometimes the result of the system } \\
\text { become zero because of the zero } \\
\text { sensing. } \\
\text { - For the exact measurement of the } \\
\text { parameters patient's body should } \\
\text { be in a horizontal state only. }\end{array}$ & $\begin{array}{l}\text { - Judgment of this structure with other is } \\
\text { to decrease the power utilization. } \\
\text { - Extends /make longer the system } \\
\text { natural life span. } \\
\text { - Make pace up the reporting } \\
\text { communication or sharing of } \\
\text { information. } \\
\text { - Improve or boost up patient's } \\
\text { excellence of life in the term of } \\
\text { independence. }\end{array}$ \\
\hline [10] & $\begin{array}{l}\text { - The unsuccessful connection of } \\
\text { routing due to violent meeting of } \\
\text { sensors. } \\
\text { - Every sensor in the environment } \\
\text { should have direct current nature } \\
\text { (charge operational nature). } \\
\text { - Ensuring for dispatching of } \\
\text { information to the right individual. }\end{array}$ & $\begin{array}{l}\text { - Such systems are applicable anywhere } \\
\text { in any instant. } \\
\text { - Such scenarios are generated for non- } \\
\text { stop or permanent surveillance, } \\
\text { watching, examination, notification } \\
\text { and dispatching of information. } \\
\text { - The compilation of meaningful data } \\
\text { without the disruption or interference } \\
\text { of mobility. } \\
\text { - These infrastructures are too } \\
\text { productive in the scenes of casualties } \\
\text { and disasters. }\end{array}$ \\
\hline [11] & $\begin{array}{l}\text { - Power utilization means } \\
\text { commonly sensor nodes include } \\
\text { the tiny battery power which in } \\
\text { turn can't be improved or } \\
\text { energized. } \\
\text { - Protection / Safety critical within } \\
\text { health care applications due to the } \\
\text { fact some sort of safety measures } \\
\text { break the rules of can lead to } \\
\text { existence harmful conditions, } \\
\text { difficulty acceptance running of } \\
\text { the system with correct output, } \\
\text { even though a few nodes are not } \\
\text { able to take part. } \\
\text { - Power utilization. } \\
\text { - Protection / safety. } \\
\text { - The difficulty, acceptance and } \\
\text { patience. } \\
\text { - Excellence of Service (QoS). }\end{array}$ & $\begin{array}{l}\text { - Low cost and tiny size devices use in } \\
\text { such assemblage of objects. } \\
\text { - Low cost and tiny dimension sensors. } \\
\text { - The real-time health concerns right } \\
\text { through the patient's body. } \\
\text { - Easily transportable applications which } \\
\text { could shift with the individual. } \\
\text { - Consistently monitoring of distinct } \\
\text { nature, alerting physicians during } \\
\text { emergencies. }\end{array}$ \\
\hline
\end{tabular}




\begin{tabular}{|c|c|c|}
\hline$[12]$ & $\begin{array}{l}\text { - The bigger volume of overhead } \\
\text { and delay require for a bunch (for } \\
\text { Cluster Selection). } \\
\text { - Avoid hotspot redirecting means } \\
\text { neglect the hotspot plotting to } \\
\text { maintain the low temp between } \\
\text { receptors. }\end{array}$ & $\begin{array}{l}\text { - To minimize the neighborhood or even } \\
\text { all-round system temp go up. } \\
\text { - Avoiding the stunning temperature go } \\
\text { up means thought behind these } \\
\text { practices is usually to option data by } \\
\text { distinct channels avoiding the stunning } \\
\text { temp increase. } \\
\text { - Minimize the volume of direct } \\
\text { transmissions from the receptors to the } \\
\text { BS. } \\
\text { - Keep active at low temp. }\end{array}$ \\
\hline [13] & $\begin{array}{l}\text { - Heterogeneous environment means } \\
\text { several files distribution model, } \\
\text { conventional methods of } \\
\text { aggregation can't be placed on } \\
\text { health care systems, nor usually } \\
\text { are energy-saving strategies that } \\
\text { make use of files compression. } \\
\text { - Scalability means just one } \\
\text { checkpoint method structure } \\
\text { seriously isn't scalable for a large } \\
\text { selection of devices. }\end{array}$ & $\begin{array}{l}\text { - Increase or improve your } \\
\text { node/network life means prolong the } \\
\text { system life/ hop. } \\
\text { - The overall efficiency metrics of the } \\
\text { system means performance of the } \\
\text { entire system. }\end{array}$ \\
\hline$[14]$ & $\begin{array}{l}\text { - The proposed gateway for the } \\
\text { health care system is just a } \\
\text { prototype and same has not been } \\
\text { implemented in the real } \\
\text { environment. } \\
\text { - The low power embedded systems } \\
\text { have been used to perform } \\
\text { different tasks including sensor } \\
\text { data, the database, DDS and } \\
\text { reports. } \\
\text { - The high-power systems may } \\
\text { create some sort of problems. } \\
\text { - The design of hardware and } \\
\text { software used in the gateway has } \\
\text { been provided. } \\
\text { - The designed protocols are not } \\
\text { reliable. }\end{array}$ & $\begin{array}{l}\text { - The main advantage of Wireless } \\
\text { Sensor Networks (WSNs) is the low } \\
\text { power consumption with the minimum } \\
\text { cost of hardware. } \\
\text { - These networks have capability of self- } \\
\text { configuration. } \\
\text { - Due to real-time data access, these } \\
\text { networks have been used for the health } \\
\text { monitoring systems. }\end{array}$ \\
\hline$[15]$ & $\begin{array}{l}\text { - The organization and type of } \\
\text { network used has not been } \\
\text { mentioned. } \\
\text { - No details have been provided that } \\
\text { on which part of the body } \\
\text { organizer must be placed? }\end{array}$ & $\begin{array}{l}\text { - The connectivity of the system with } \\
\text { GPS provides an advantage that the } \\
\text { hospital management can easily trace } \\
\text { the position of a patient in case of } \\
\text { emergency. } \\
\text { - The web based data management } \\
\text { provides more accessibility and } \\
\text { improved availability. }\end{array}$ \\
\hline [16] & $\begin{array}{l}\text { - The battery timing is the issue in } \\
\text { this system. } \\
\text { - The data confidentiality cannot be } \\
\text { ensured in mobile adhoc networks. } \\
\text { - The devices have limited memory }\end{array}$ & $\begin{array}{l}\text { - The system uses SMS for the quick } \\
\text { notification to the specific doctor. } \\
\text { - The monitoring is automatic that's } \\
\text { why any involvement of the attendant/ } \\
\text { nurse is not required. }\end{array}$ \\
\hline
\end{tabular}




\begin{tabular}{|c|c|c|}
\hline & $\begin{array}{l}\text { and computation power. } \\
\text { - The system has the disadvantage } \\
\text { that for each patient a separate } \\
\text { device is required which increased } \\
\text { the cost of equipment. } \\
\text { - The increase in number of patient } \\
\text { will increase the load on system } \\
\text { network that may lead to network } \\
\text { failure or delay in transmission of } \\
\text { data. } \\
\text { - The increase in data traffic may } \\
\text { also cause complete network } \\
\text { failure. } \\
\text { - Zigbee is not suitable for the high } \\
\text { bit rate devices. }\end{array}$ & $\begin{array}{l}\text { - No wired infrastructure is involved. } \\
\text { - The sensors are low powered high } \\
\text { memory devices. } \\
\text { - The adhoc network is easier to } \\
\text { establish. } \\
\text { - Due to Zigbee network use of physical } \\
\text { buses has been eliminated. } \\
\text { - Mesh network provides higher } \\
\text { availability. } \\
\text { - The GSM has an advantage of } \\
\text { international roaming, low cost devices } \\
\text { and compatibility with ISDN. } \\
\text { - The SMS is globally accepted method } \\
\text { of transmission of short messages. }\end{array}$ \\
\hline [17] & $\begin{array}{l}\text { - The cloud is not secure the data } \\
\text { can be accessed by a third party } \\
\text { un-authorized person. } \\
\text { - The SMS alert has not been } \\
\text { included in case of critical } \\
\text { condition of patient. }\end{array}$ & $\begin{array}{l}\text { - Sensor data has been ported on a cloud } \\
\text { network which provides scalability, } \\
\text { centralized user access, without } \\
\text { maintenance cost. } \\
\text { - The tiny wearable bio sensors are easy } \\
\text { to wear and do not affect the } \\
\text { movement of a patient. } \\
\text { - The complete history of patient can be } \\
\text { easily accessed through centralized } \\
\text { database. } \\
\text { - The patients equipped with body } \\
\text { sensor network need not to be } \\
\text { physically present for diagnosis. }\end{array}$ \\
\hline
\end{tabular}

\subsection{Limitations of Health Care Systems}

Despite several advancements in healthcare systems they still have some limitations. The wireless body area networks have limited battery timing. The increase in sensing points increases the data generation which leads to more battery consumption. The response time should be minimum, but sometimes it increases due to the slow network [21]. The computation power of handheld devices used in healthcare systems is limited. The operational heat of the equipment and un-availability of wireless network sometimes cause the delay in the transmission of data or can harm the hardware. The continuous placement of sensors on the patient body may cause skin problems, in some scenarios a burning of skin has been reported. The batteries drain instantly which can cause the interruption of data transmission and may lead to a critical problem for a patient in an emergency condition. The networks are built in open areas where the data is exposed to different attacks already discussed in detail. The sensitive data can also be tempered [22].

The good Quality of Services (QoS), safety measures, solitude (privateness), fault patience, electricity intake are the main issues. Sometimes the individual is completely surpassed by alerts which are harmful to the human body on the people within the reasonable length of time. The constant power towards human body sensor nodes, the heterogeneous natural environment within expression involving direction-finding is lying down with respect to these systems. These issues need to be settled for superior and efficient deployment of such systems which meet the standards of the health industry. 


\section{Conclusion and Future Work}

The literature focus on WSN, WBAN, WBSN, in relation to operating characteristics, distinct materials and features of the techniques, applications of the techniques in different fields of lifestyle. These techniques are still newly released in neuro-scientific health care and professional medical environment. These techniques use enormous potential to be able to revolutionize medical while using the unique variations of supervising through checking out and offer real-time patient supervising including patient's heartbeat monitoring, blood strain monitoring as well as other critical supervising with the medical center, residence come in some other spot regarding disaster. Some advantages of the techniques are long network life, accelerate and runs this connection protection, improve patient's lifestyle, and lower affected individuals. The dangers of severity throughout disaster conditions and delivering these people an agreeable natural environment with the medical center, residence, and with the spot that the substantial casualties usually arise.

It is clear from the literature that the Healthcare systems mostly face the issue of data security. Keeping in mind the security of the networks used by healthcare systems we will focus on the encryption methods so that the important data of the patient can be secured and transmitted through encryption method. The data encryption will increase the security of data and in case if the data security has been compromised still the data will not be readable without proper decryption method.

\section{References}

[1] K. Grgić, D. Žagar, and V. Križanović, "Medical Applications of Wireless Sensor NetworksCurrent Status and Future Directions", MedicinskiGlasnik, vol. 9, no 1, (2012), pp. 23-31.

[2] G. Kambourakis, E. Klaoudatou, and S. Gritzalis, "Securing Medical Sensor Environment: The CodeBlue Framework Case", The second International Conference on Availability, Reliability, and Security, (2007) April 10-13.

[3] F. Touati and Rohan Tabish, "U-Healthcare System: State-of-the-Art Review and Challenges", Journal of Medical Systems, (2013).

[4] S. H. Kim, D.W. Ryoo and C. Bae, "U-healthcare System using Smart Headband", In proc. of $30^{\text {th }}$ Annual International Conference of the IEEE Engineering in Medicine and Biology Society, 08 (2008), pp. 1557-1560.

[5] M. S. Shin, H. S. Jeon, Y. W. Ju and S-P. Jeong, "Constructing RBAC Based Security Model in u-Healthcare Service Platform", The Scientific World Journal, (2015), pp. 1-13.

[6] M. Shah and A. S. Shah, "Appraisal of the Most Prominent Attacks due to vulnerabilities in cloud computing", International Journal of Grid and Distributed Computing (IJGDC), vol. 9, no. 7, (2016), pp. 13-22.

[7] M. Shah and A. S. Shah, "Implementing User Authentication as a Service for Cloud Network," International Journal of Grid and Distributed Computing (IJGDC), vol. 9, no. 10, (2016), pp. 197-210.

[8] J. G. Ko, C. Lu, M. B. Srivastava, J. A. Stankovic, A. Terzis and M. Welsh, "Wireless Sensor Networks for Healthcare", Proceedings of the IEEE, vol. 98, no 11, (2010), pp. 1947-1960.

[9] M. Aminian, and H. R. Naji. "A Hospital Healthcare Monitoring System using Wireless Sensor Networks", Journal of Health Med. Inform., vol. 4, no 2, (2013), pp. 1-6.

[10] K. P. Wagh and S. O. Rajankar, "Wireless Body Area Network: Real-Time Health Monitoring System", IJCA, Proceedings on National Conference on Advancement in Electronics and Telecommunication Engineering, NCAETE, vol. 1, (2012), pp. 7-11.

[11] I. M. Khan, N. Jabeur, M. Z. Khan and H. Mokhtar, "An Overview of the Impact of Wireless Sensor Networks in Medical Health Care", 1st International conference on Computers and Information Technology (ICCIT), Saudi Arabia, (2012), pp. 576-580.

[12] S. Movassaghi and M. Abolhhasn, "A Review of Routing Protocols in Wireless Body Area Networks", Journal of Networks, vol. 8, no. 3, (2013), pp. 559-575.

[13] W-Y. Chung, S-M. An and S-C. Lee, "Real Time Multi-hop Routing Protocol for Healthcare System Based on WSN", 14 ${ }^{\text {th }}$ International Meeting on Chemical Sensors, (2012), pp. 12531256. 
[14] D. M. Kumar, "Healthcare monitoring system using Wireless Sensor Network", International Journal of Advanced Networking and Applications, vol. 4, no. 1, (2012), pp. 1497-1500.

[15] R. Rajeswari, "A Healthcare Monitoring System using Wireless Sensor Network with GSM", International Research Journal of Engineering and Technology, vol. 4, no. 2, (2017), pp. 463465.

[16] B. Vijayalakshmi and C. Ram Kumar, "Patient Monitoring System using Wireless Sensor Based Mesh Network", In Proc. of 2012 Third International Conference on, Computing Communication \& Networking Technologies (ICCCNT), (2012) July 26-28.

[17] S. Babu, M. Chandini, P. Lavanya, K. Ganapathy and V. Vaidehi, "Cloud-enabled remote health monitoring system", 2013 International Conference on Recent Trends in Information Technology (ICRTIT), (2013).

[18] 52 North SOS, http://52north.org/

[19] CloudBees PaaS, http://www.cloudbees.com

[20] P. Neves, M. Stachyra and J. Rodrigues, "Application of Wireless Sensor Networks to Healthcare Promotion", Journal of Communications Software and Systems (JCOMSS), vol. 4(3). Croatian Communications and Information society, in cooperation with FESB, University of Split, Croatia, (2008), pp. 181-190.

[21] S. L. Rahane and P. R. S. Pawase, "A Healthcare Monitoring System using Wireless Sensor Network with GSM", International Journal of Advanced Research in Electrical, Electronics and Instrumentation Engineering, vol. 4, no. 7, (2015), pp. 6330-6335.

[22] N. R. Pandya, V. K. Bhosale and R. M. Autee, "Wireless Sensor Based Handy Patient Monitoring System", 2016 IEEE 6th International Conference on, Advanced Computing (IACC), (2016) February 27-28.

\section{Authors}

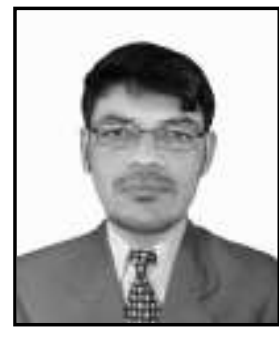

Jawad Ahmad Aman, has completed MS degree in Computer Science from SZABIST, Islamabad, Pakistan in 2015. He did his BS degree in Information Technology Science from KUST, Kohat Pakistan in 2010.

He has completed short courses and diploma certificates in MCSE (Windows Server 2008), Linux, Cyber Security and Networking.

His research area includes Cloud Computing, Cyber Security, and Cryptography.

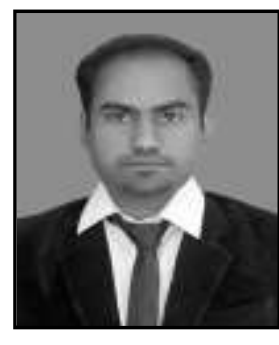

Abdul Salam Shah, is currently perusing Doctor of Philosophy (Information Technology) at Malaysian Institute of Information Technology, University of Kula-Lumpur (UniKL), Kula-Lumpur, Malaysia. Furthermore, he has completed MS degree in Computer Science from SZABIST, Islamabad, Pakistan in 2016. He did his BS degree in Computer Science from Isra University Hyderabad, Sindh Pakistan in 2012. In addition to his degree, he has completed short courses and diploma certificates in Databases, Machine Learning, Artificial Intelligence, Cybercrime, Cybersecurity, Networking, and Software Engineering.

He has completed specialization in Management Information System (MIS) from Virtual University of Pakistan in 2017. He has published articles in various journals of high repute. His research area includes Machine Learning, Artificial Intelligence, Digital Image Processing, Cybersecurity, and Data Mining. 
International Journal of Advanced Science and Technology

Vol.109 (2017) 